University of Nebraska - Lincoln

DigitalCommons@University of Nebraska - Lincoln

$12-2012$

\title{
On the Importance of Modeling Stent Procedure for Predicting Arterial Mechanics
}

\author{
Shijia Zhao \\ University of Nebraska-Lincoln, s-szhao3@unl.edu \\ Linxia Gu \\ University of Nebraska-Lincoln, gul@fit.edu \\ Stacey R. Froemming \\ Children's Hospital and Medical Center, Omaha, NE
}

Follow this and additional works at: https://digitalcommons.unl.edu/mechengfacpub

Part of the Biomedical Devices and Instrumentation Commons, and the Cardiology Commons

Zhao, Shijia; Gu, Linxia; and Froemming, Stacey R., "On the Importance of Modeling Stent Procedure for Predicting Arterial Mechanics" (2012). Mechanical \& Materials Engineering Faculty Publications. 86. https://digitalcommons.unl.edu/mechengfacpub/86

This Article is brought to you for free and open access by the Mechanical \& Materials Engineering, Department of at DigitalCommons@University of Nebraska - Lincoln. It has been accepted for inclusion in Mechanical \& Materials Engineering Faculty Publications by an authorized administrator of DigitalCommons@University of Nebraska Lincoln. 


\section{On the Importance of Modeling Stent Procedure for Predicting Arterial Mechanics}

Materials Engineering

University of Nebraska-Lincoln,

Lincoln, NE 68588-0656

\author{
Linxia Gu' \\ Department of Mechanical and \\ Materials Engineering, \\ University of Nebraska-Lincoln, \\ Lincoln, NE 68588-0656 \\ Nebraska Center for Materials and Nanoscience, \\ Lincoln, NE 68588-0656 \\ e-mail: Igu2@unl.edu
}

\section{Stacey R. Froemming \\ Hybrid Catheterization and \\ Electrophysiology Laboratory, \\ Children's Hospital and Medical Center, Omaha, NE 68114-4133}

The stent-artery interactions have been increasingly studied using the finite element method for better understanding of the biomechanical environment changes on the artery and its implications. However, the deployment of balloon-expandable stents was generally simplified without considering the balloon-stent interactions, the initial crimping process of the stent, its overexpansion routinely used in the clinical practice, or its recoil process. In this work, the stenting procedure was mimicked by incorporating all the above-mentioned simplifications. The impact of various simplifications on the stentinduced arterial stresses was systematically investigated. The plastic strain history of stent and its resulted geometrical variations, as well as arterial mechanics were quantified and compared. Results showed the model without considering the stent crimping process underestimating the minimum stent diameter by $17.2 \%$, and overestimating the maximum radial recoil by $144 \%$. It was also suggested that overexpansion resulted in a larger stent diameter, but a greater radial recoil ratio and larger intimal area with high stress were also obtained along with the increase in degree of overexpansion. [DOI: 10.1115/1.4023094]

Keywords: balloon-expandable stent, interface, crimping, overexpansion, recoil, modeling techniques

\section{Introduction}

Stents have been widely used to treat arterial occlusions by mechanically enlarging the blocked artery and restoring blood flow. Balloon-expandable stents are required to be crimped onto the balloon catheters forming a low profile for efficient delivery. When the catheter is advanced to the blocked artery, the balloon is inflated to plastically deform the stent to expand the occluded vessel outwards. The stent will stay in place to support the blocked artery, while the balloon is deflated and withdrawn with the catheter. It is acknowledged that stent implantation induced abnormal arterial stretches and stresses, which stimulates and injures the vessel wall, leading to the in-stent restenosis, a major complication of stenting [1-4]. In order to optimize the stent design to alleviate the arterial stress concentrations and its resulting complications, it is vital to better predict the biomechanics of a stented artery.

Finite element analysis has been proven as an efficient tool to investigate the mechanics at the interface among the balloon, stent, and stenotic artery [5-9]. However, the existing modeling of balloon-expandable stents was generally simplified without considering the balloon-stent interactions, the initial crimping process of the stent, its overexpansion routinely used in the clinical practice, or/and its recoil process. The main objective of this work is to systematically study the impact of the abovementioned simplifications on the stented artery. The obtained results will provide a better understanding of the physics of balloon-stent-artery interactions with respect to changes in modeling techniques.

\footnotetext{
${ }^{\mathrm{I}}$ Corresponding author

Contributed by the Bioengineering Division of ASME for publication in the Journal of Biomechanical Engineering. Manuscript received July 9, 2012; final manuscript received November 3, 2012; accepted manuscript posted November 28, 2012; published online December 5, 2012. Assoc. Editor: Tim David.
}

\section{Methods}

The three-dimensional model of the stenting process was developed in the commercial finite element code ABAQUS (Dassault Systèmes Simulia Corp., Providence, RI, USA), as depicted in Fig. 1. The commercial express stent (Boston Scientific, Natick, MA, USA) was implanted into a coronary artery with lumen diameter of $3 \mathrm{~mm}$, wall thickness of $0.75 \mathrm{~mm}$, and length of $26 \mathrm{~mm}$ $[10,11]$. The asymmetric plaque has a parabolic longitudinal profile with a length of $13 \mathrm{~mm}$. An edge ratio of 2: 1 at the narrowest occlusion leads to the lumen diameter of $1.5 \mathrm{~mm}$, which is $50 \%$ of the reference lumen, referred to as $50 \%$ stenosis. The stent was first crimped from its nominal diameter of $3.0 \mathrm{~mm}$ onto the balloon with a crimped diameter of $1.2 \mathrm{~mm}$ and a length of $17 \mathrm{~mm}$. Then it was balloon-expanded back to its original nominal diameter. When the balloon withdrew, the stent recoiled back. Both the stent crimping and expansion were achieved by applying uniform displacements onto the crimper and balloon, respectively.

2.1 Material Models. The express stent is made of $316 \mathrm{LN}$ stainless steel, whose mechanical behavior was described as the perfect linear elastic-plastic material. The corresponding material parameters are Young's modulus $E=190 \mathrm{GPa}$, Poisson's ratio $\nu=0.3$, and yield stress $\sigma_{\mathrm{Y}}=207 \mathrm{MPa}$.

The arterial wall was tested as an isotropic hyperelastic material, while the plaque was modeled using the isotropic hyperelastic-plastic constitutive equation (Fig. 2). The hyperelastic material was described by a third-order polynomial strain energy density function $U$ as

$$
U=\sum_{i+j=1}^{3} C_{i j}\left(I_{1}-3\right)^{i}\left(I_{2}-3\right)^{j}
$$

where the $I_{1}$ and $I_{2}$ are the first and second invariants of the Cauchy-Green tensor, defined as $I_{1}=\lambda_{1}^{2}+\lambda_{2}^{2}+\lambda_{3}^{2}$ and $I_{2}=\lambda_{1}^{-2}+\lambda_{2}^{-2}+\lambda_{3}^{-2}$, where $\lambda_{i}$ are the principal stretches. $C_{i j}$ are 


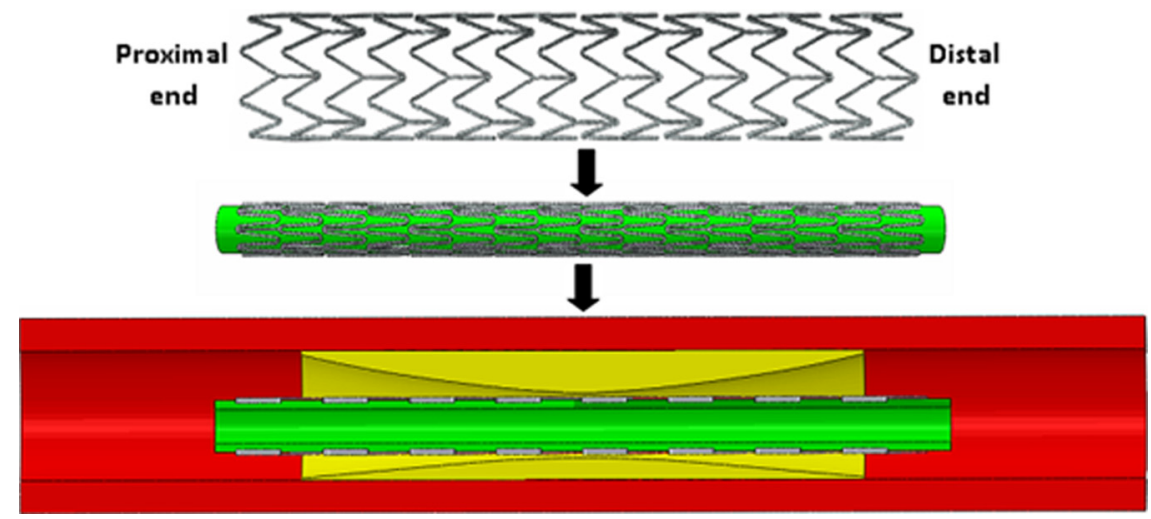

Fig. 1 The three-dimensional model of the complete stenting system before expansion: nominal state (top), crimped state (middle), and delivery to target lesion (bottom)

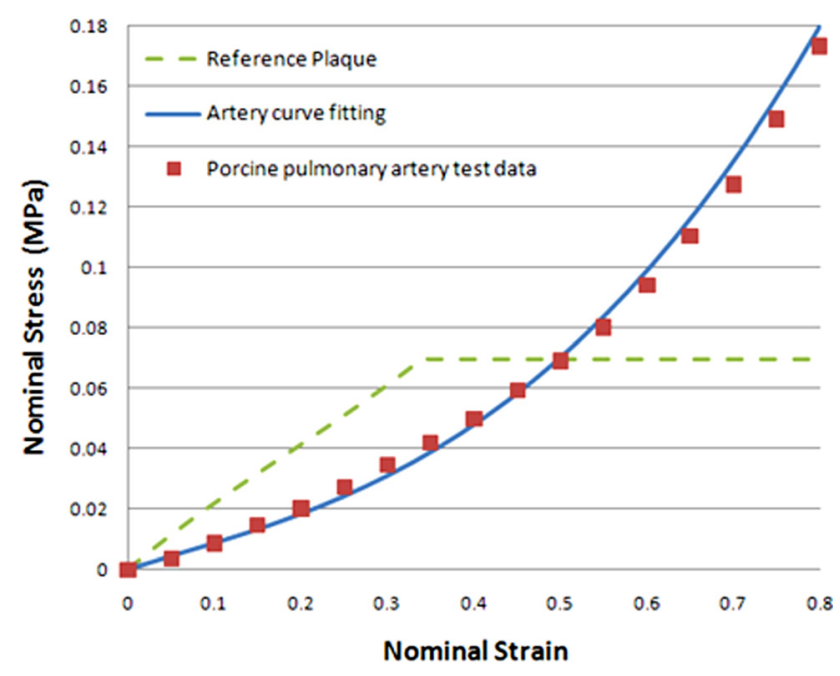

Fig. 2 Mechanical behavior of artery and plaque

material coefficients determined by fitting the experimental stressstrain data. The material coefficients for arterial wall, $C_{10}=0.014$ $881 \mathrm{MPa}, C_{20}=0.014920 \mathrm{MPa}$, and $C_{30}=0.00093934 \mathrm{MPa}$, were obtained from our previous test data [12]. The material coefficients for the hyperelastic plaque, $C_{10}=0.04 \mathrm{MPa}$, $C_{02}=0.003 \mathrm{MPa}$, and $C_{03}=0.02976 \mathrm{MPa}$, were adopted from published data $[13,14]$. The perfect plastic model was used to describe the permanent deformation of the plaque, which is necessary for modeling the stent recoil process [9]. The plasticity was assumed to initiate at $34 \%$ strain [15], corresponding to a calculated stress level of $0.07 \mathrm{MPa}$ as shown in Fig. 2.

2.2 Mesh and Boundary Conditions. The stent was meshed with 4-node general shell elements S4R, which has been validated by Avdeev et al. [16]. Reduced 8-node brick elements C3D8R were used for the plaque and artery. The element sizes of $0.12 \mathrm{~mm}$ and $0.14 \mathrm{~mm}$ for plaque and artery, respectively, were adopted based on the mesh convergence study. The two ends of the artery were constrained as symmetrical planes. A general contact algorithm was used for all the contact pairs. A friction coefficient of 0.05 was adopted at the tissue-stent interface based on the measurements conducted by Dunn et al. [17].

\section{Results}

The full stenting process, including stent crimping, balloon expansion at the diseased lesion site, and its recoil with the deflation of balloon, was simulated as the baseline data. The effects of stent crimping and overexpansion on the stented artery were then evaluated.

3.1 The Stent Behavior: From Crimping to Recoil. The stent was first uniformly crimped from its nominal diameter of $3 \mathrm{~mm}$ to a small profile of $1.2 \mathrm{~mm}$, and the stent length was increased from 15.74 to $16.01 \mathrm{~mm}$. After delivery to the target lesion, the stent was then expanded uniformly to $3.39 \mathrm{~mm}$, which is $13 \%$ larger than its nominal diameter [18]. The deflation and withdrawal of balloon catheter led to the stent recoil back with a final length of $15.88 \mathrm{~mm}$ and diameters of 3.32, 3.03, and $3.31 \mathrm{~mm}$ at its proximal end, center, and distal end, respectively (Table 1). It is obvious that the stent exhibited a dogbone shape with smaller dimensions in the central zone. This is due to the parabolic plaque profile. The dogboning effect, defined as the relative difference between the central diameter and the average diameter at two ends, was calculated as $8.60 \%$. In addition, the foreshortening of the stent, which is defined as the change in its axial length during the expansion, was evaluated as $0.81 \%$. The radial recoils were calculated as $2.06 \%, 10.62 \%$, and $2.36 \%$ at its proximal end, center, and distal end, respectively.

From the crimping to the recoil of the balloon-expandable stent, large irreversible plastic deformation was induced, which determined the scaffolding performance of the stent. The equivalent plastic strain (PEEQ) history at one specific location, with the peak PEEQ after full expansion, was plotted in Fig. 3. It is clear that the PEEQ was accumulated from the crimping until the full expansion of the stent, and then kept as a plateau during the recoil process. The contour plot of the PEEQ in Fig. 4 shows that the PEEQ concentrated around the curved crowns of the stent, whose

Table 1 Stent performance after being implanted in a $\mathbf{5 0 \%}$ stenosed artery

\begin{tabular}{|c|c|c|c|c|c|}
\hline & \multicolumn{3}{|c|}{ Diameter (radial recoil $\left.1-D_{\text {location }}^{\text {Unload }} / D_{\text {location }}^{\text {Load }}\right)$} & \multirow[b]{2}{*}{ Dogboning $1-\frac{D_{\text {Center }}}{\frac{D_{\text {Proximal }}+D_{\text {Distal }}}{2}}$} & \multirow[b]{2}{*}{ Foreshortening $1-l_{\text {final }} / l_{\text {crimpec }}$} \\
\hline & Proximal end & Center & Distal end & & \\
\hline $\begin{array}{l}\text { With } \\
\text { crimping }\end{array}$ & $\begin{array}{l}3.32 \mathrm{~mm} \\
(2.06 \%)\end{array}$ & $\begin{array}{l}3.03 \mathrm{~mm} \\
(10.62 \%)\end{array}$ & $\begin{array}{l}3.31 \mathrm{~mm} \\
(2.36 \%)\end{array}$ & $8.60 \%$ & $0.81 \%$ \\
\hline $\begin{array}{l}\text { Without } \\
\text { crimping }\end{array}$ & $\begin{array}{l}2.80 \mathrm{~mm} \\
(17.40 \%)\end{array}$ & $\begin{array}{l}2.51 \mathrm{~mm} \\
(25.96 \%)\end{array}$ & $\begin{array}{l}2.78 \mathrm{~mm} \\
(17.99 \%)\end{array}$ & $10.04 \%$ & $1.25 \%$ \\
\hline
\end{tabular}




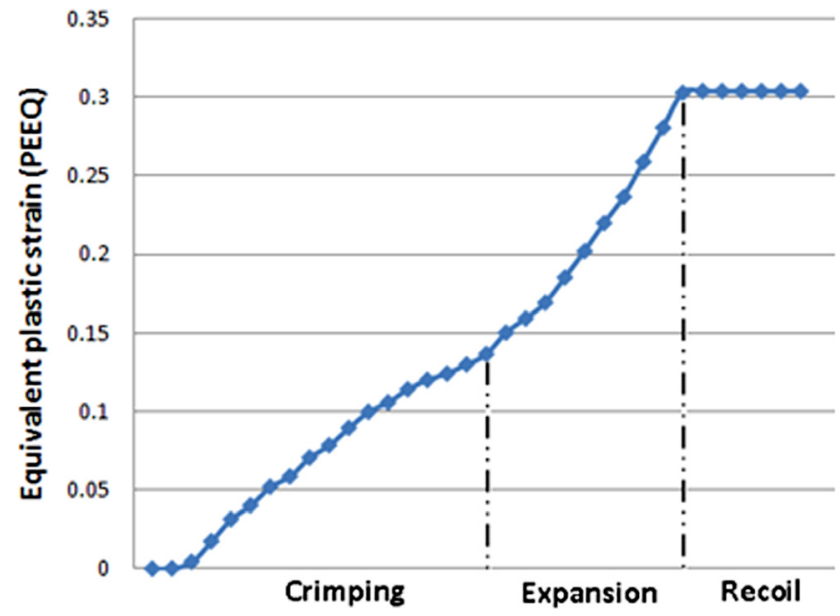

Fig. 3 The equivalent plastic strain (PEEQ) variation during the stenting process

geometry parameters are the critical design factors for optimization of stent scaffolding ability [19]. The PEEQ of the stent after its full expansion was $30.25 \%$ at maximum, as shown in the Fig. 3, while it was $13.65 \%$ after the crimping process at this location. The maximum PEEQ after crimping was $15.67 \%$, and occurred at different locations of the stent. The percentage of the stent surface with plastic deformation (PEEQ $\geq 0.1 \%$ ) after the crimping process was $67.62 \%$, while it was $82.90 \%$ after full expansion, indicating a $22.60 \%$ relative increase.

3.2 The Arterial Mechanics. During the balloon-induced stent expansion process, the stent pushed the lesion outwards and resulted in abnormal stresses on the artery. The radial strength of the stent, defined as the maximum contact pressure between the stent and artery wall, was used to quantify the scaffolding capacity of the stent, as well as the collapse resistance against the radial compressive loads from the artery wall [19]. As the stent was fully expanded to the diameter of $3.39 \mathrm{~mm}$, the radial strength was $0.16 \mathrm{MPa}$, while it was reduced to $0.13 \mathrm{MPa}$ after stent recoil. This led to the similar observations for the peak principal stresses on the artery, which was $118.6 \mathrm{kPa}$ before the stent recoil, and became $72.93 \mathrm{kPa}$ after the recoil. The recoil process reduced the peak arterial stress by $38.51 \%$. The contact pressure map on the plaque, as well as the maximum principal stress map on the artery before and after stent recoil, were depicted in Figs. 5 and 6, respectively. It is clear that the isostress contour maps before and after the recoil process showed a similar pattern; even the stent recoil alleviated the peak contact pressure, as well as the maximum principal stress. The probability distributions of maximum principal stress on the inner surface of the artery before and after stent recoil were plotted in Fig. 7. The most frequently occurring stress before and after recoil appeared within the same range, and the probability of this stress state increased after recoil. In contrast, the tail region of the least frequently occurring stress values reduced after recoil, especially for stress values larger than
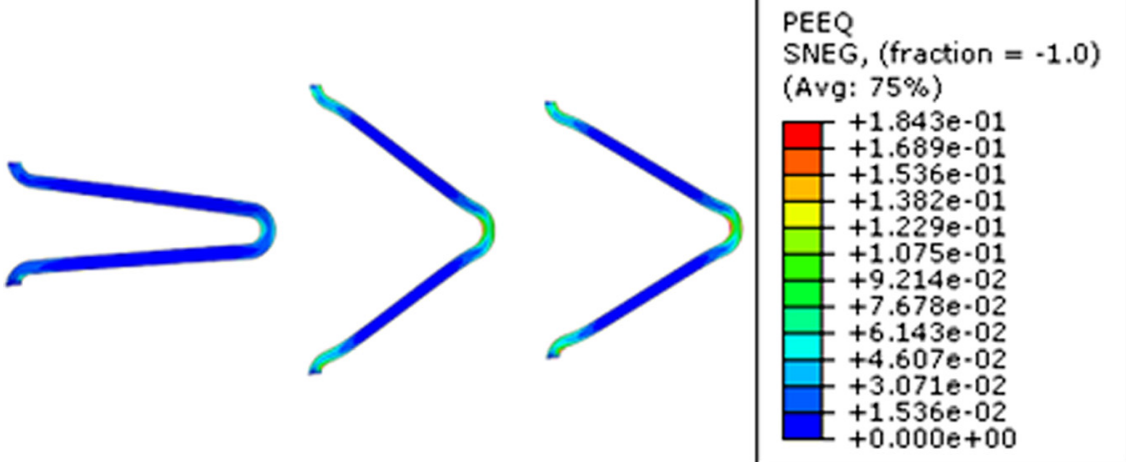

Fig. 4 The contour plot of the PEEQ of the stent unit at crimping state (left), fully expanded state (middle), and equilibrium state after recoil (right)
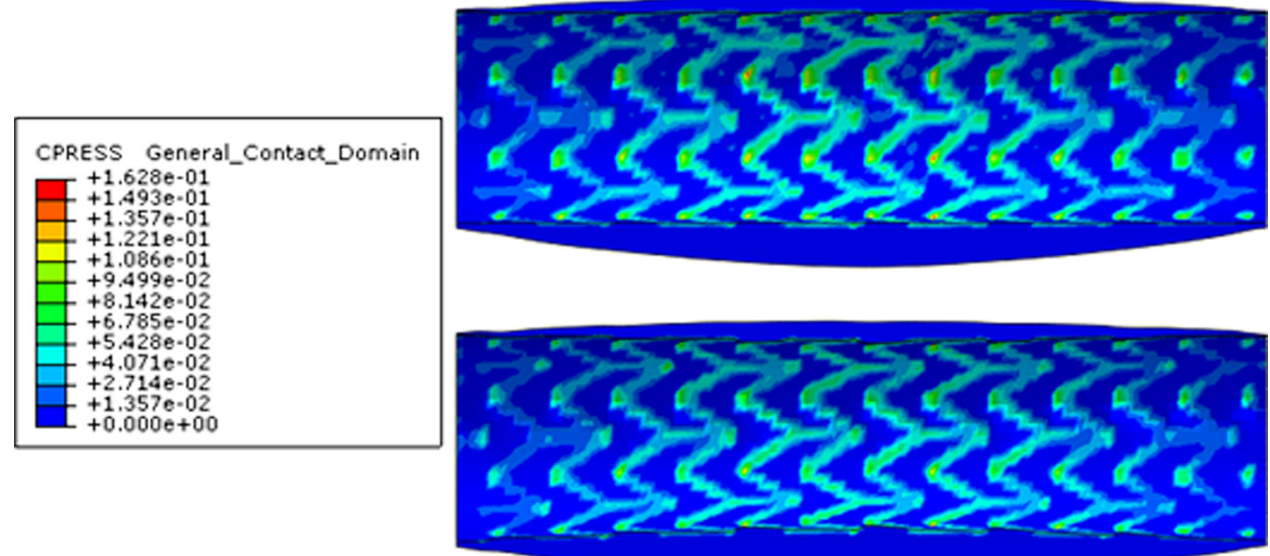

Fig. 5 The contact pressure distribution on the plaque at the fully expanded state of the stent (top) as well as after stent recoil (bottom) 


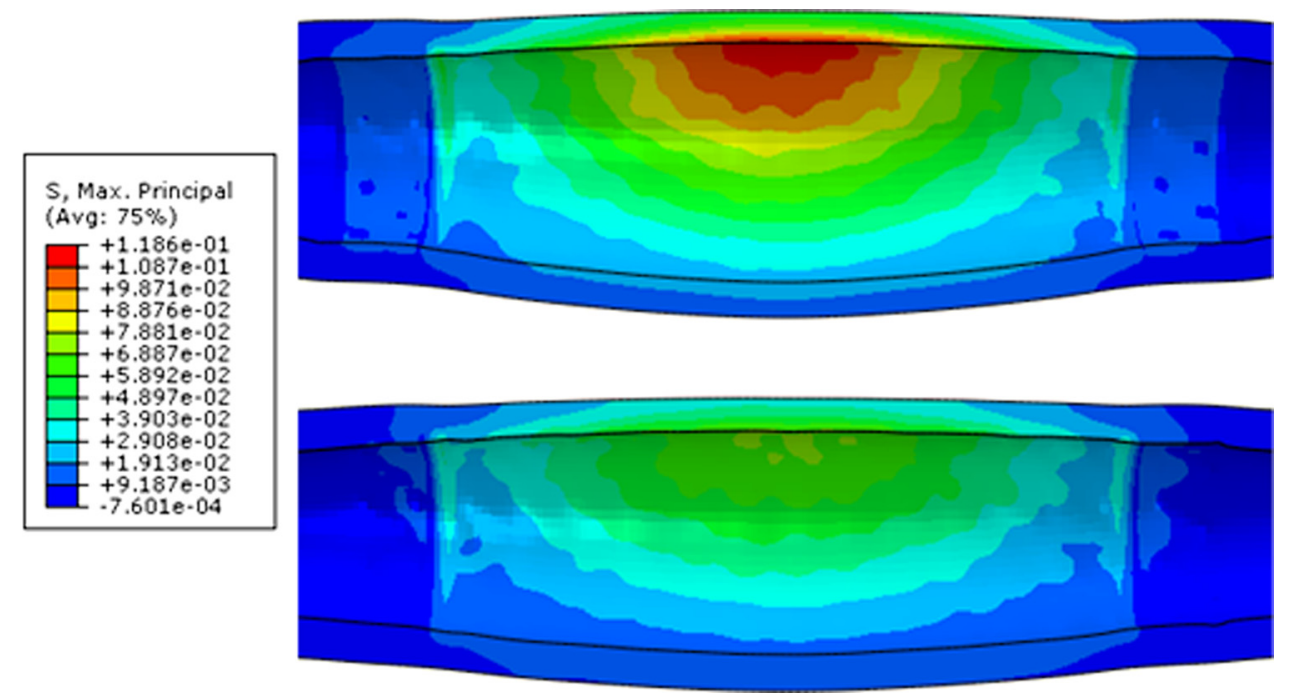

Fig. 6 The maximum principal stress map on the artery at the fully expanded state of the stent (top) as well as after stent recoil (bottom)

$80 \mathrm{kPa}$. It demonstrates that the stent recoil significantly altered the peak stress component and the stress distributions.

3.3 Effect of Stent Overexpansion. The stent's ability of opening the occluded lumen is adversely affected by the radial recoil; thus the stent is usually overexpanded by $10 \%-20 \%$ of the reference lumen diameter to compensate for the elastic recoil of the stent [18]. In the baseline model, the stent was overexpanded by $13 \%$ of the reference lumen diameter, and then reached a center diameter of $3.03 \mathrm{~mm}$ after recoil. To understand the effect of stent overexpansion on the overall mechanical behavior of a stent, the stent was expanded to $3.48 \mathrm{~mm}$ and $3.60 \mathrm{~mm}$, i.e., overexpanded by $16 \%$ and $20 \%$ of the reference lumen diameter. Results have shown that the corresponding minimal diameters of the stent after stent recoil were $3.08 \mathrm{~mm}$ and $3.15 \mathrm{~mm}$, respectively. This indicates that a greater degree of overexpansion leads to a larger acute lumen gain. The effect of overexpansion on the percentage of radial recoil, foreshortening as well as the PEEQ of stent were quantified in Fig. 8. The three solid lines correspond to the percentage of recoil rate at various locations of the stent. The dashed line represents the trend of maximum PEEQ in the stent, and the dashed-dotted line denotes the foreshortening of the stent. It is obvious that the percentage of radial recoil increased with a larger overexpansion diameter, especially at the center location, which is also the limiting lumen dimension. Meanwhile, the stent foreshortening and the PEEQ also increased. All these characterizations of

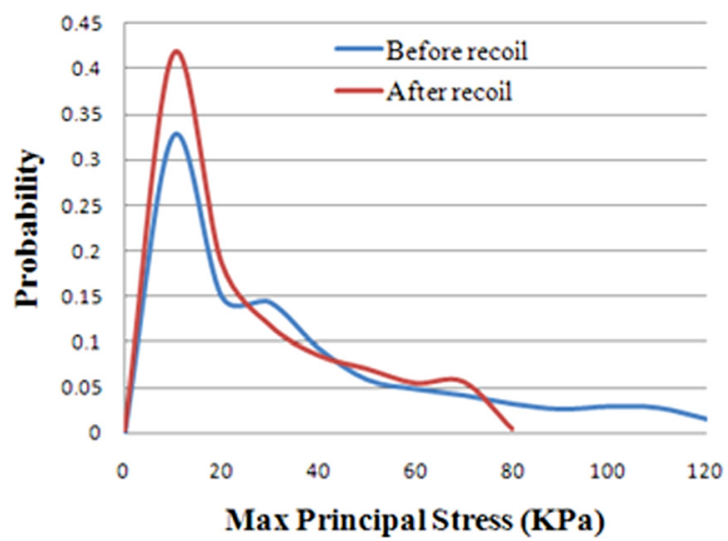

Fig. 7 The probability distribution of maximum principal stress on the intima stent are desired to be as small as possible to minimize the operational injury [20]. In addition, the most frequently occurring stress was also within the same range, and the probability of this stress state reduced with more overexpansion, as shown in Fig. 9. In contrast, the tail region of higher stresses increased with a larger frequency. The overexpansion resulted in a probability shift from most frequently occurring stress to the tail region with larger stresses on the intimal surface of the artery. The larger stress region is generally correlated with the artery injury. This indicates that the overexpansion is not desirable procedure even though it leads to larger acute lumen gain and is routinely used in the clinical practice.

3.4 Effect of Stent Crimping. Most of the numerical models on the stenting process failed to consider the crimping phase of the stent [21-23]. To evaluate the effect of stent crimping on its performance, the above-mentioned stenting process was modified to exclude the crimping phase, i.e., expand the stent from its crimped profile as the original stress-free state. The remaining process was kept the same as the baseline model. The minimum stent diameter after recoil was $2.51 \mathrm{~mm}$ at its central section. The corresponding recoil rate was calculated as $25.96 \%$, which is much greater than the recoil rate of $10.62 \%$ for the baseline case considering the crimping phase. The stent behavior with and

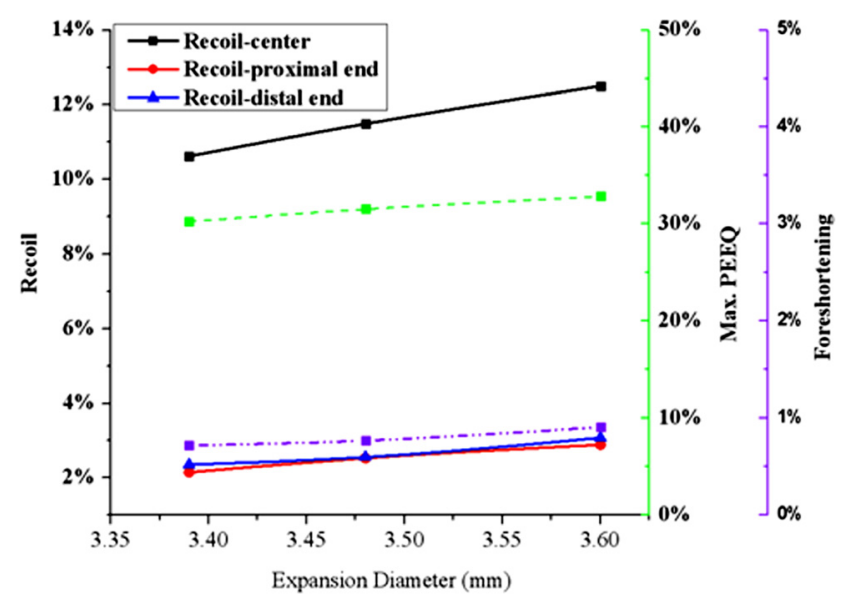

Fig. 8 The impact of overexpansion on the radial recoil, foreshortening, as well as PEEQ of the stent 


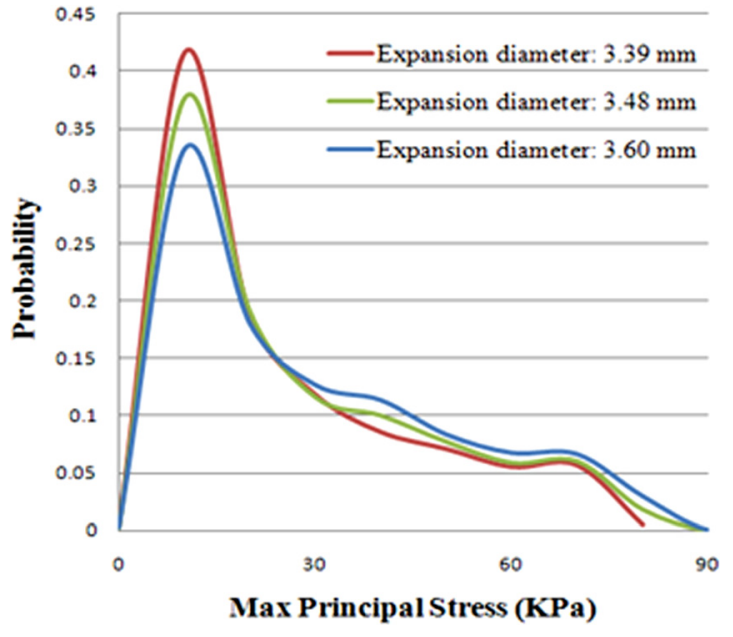

Fig. 9 The impact of overexpansion on the probability distribution of maximum principal stress on intima after recoil

without considering the crimping phase were compared and listed in Table 1. It is clear that the final diameter of the stent is much less without considering the crimping phase. The stent recoil rate, dogboning effect, and its foreshortening increased, which are not desirable. However, the maximum principal stresses on the artery wall decreased significantly from $72.93 \mathrm{kPa}$ in the case with the crimping phase, to $32.49 \mathrm{kPa}$ found in the case without the crimping phase. The peak PEEQ after recoil was $30.36 \%$ with the crimping phase, in contrast to the $19.41 \%$ in the case without crimping.

\section{Discussion}

In this work, the process of stent deployment, including crimping, expansion, and recoil phases, was systematically analyzed using the finite element method. The stent was first crimped from its nominal dimension onto the catheter by the radial compression of a crimper. Then it was expanded by the displacementcontrolled balloon [22]. The adopted modeling techniques were verified by our in vitro stent expansion test [3], as well as the work by De Beule et al. [23] and Mortier et al. [24]. When the balloon was deflated and withdrawn, the elasticity of the stent led to its recoil, which formed the stent into a dogbone shape. Less recoils were observed at two ends of the stent due to the less constraints as well as less loadings from the diseased lesion, which is consistent with the observations by Zahedmanesh et al. [25]. The calculated radial recoil ratios (Table 1) are within the reported recoil range of $12 \pm 16 \%$ [26]. The plasticity of the stent was utilized to sustain the in vivo loadings and serve as the scaffold to hold the artery open. The maximum PEEQ on stent after crimping is $15.67 \%$, while it is $30.25 \%$ after full expansion of the stent. The plastic strain concentrations occurred at the crown junction of the stent appears to be related to the fracture of the stent $[19,27]$. The radial strength of the stent depends on the contact pressure at the stent-lesion interface. Higher radial strength at the full expansion of the stent led to a higher outwards contact pressure (Fig. 5), and also the larger arterial stresses (Fig. 6). The elastic recoil of the stent reduced its radial strength by $18.75 \%$. However, smaller radial strength might lead to the migration of the stent [28]. In contrast, the recoil relieved the peak arterial stresses by $38.51 \%$ as well as the percentage area of high stress $(>80 \mathrm{kPa})$ by $10.14 \%$ (Fig. 7), which is related to less vascular injury [6].

During the routine clinical operations, the stent is required to be overexpanded to compensate for the elastic recoil and arterial compression and reach a certain reference diameter of the lesion. The overexpansion is currently done by trial and error method. The extent of the overexpansion will affect the clinical outcomes
[29]. We observed that the overexpansion indeed led to the increased lumen size. However, it also resulted in larger recoil, foreshortening, overstretch of the arterial wall, relatively larger probability in high stress range, as well as peak arterial stress, which are not desirable due to their adverse effect on the vascular injury. This trend contradicts the observation for the overexpansion of bare metal stent [30], which indicates that the performance of the stent is significantly affected by the interaction between the stent and the diseased lesion. Therefore, the appropriate overexpansion diameter depends on the compromise between the minimal lumen diameter and the arterial stress, etc. [31].

The crimping procedure also significantly affects the performance of the stent as well as its resulting arterial mechanics. Plastic deformation of the stent is an accumulative process as shown in Fig. 3. Neglecting the crimping procedure led to $36 \%$ reduction in the maximum PEEQ, and thus relative larger elastic recoil. This implied a smaller lumen diameter, less acute lumen gain, and less arterial stresses on the artery wall. Our observations are in agreement with the experimental work by Moller et al. [32], which has also stated that the addition of the crimping phase induced a much higher level of plastic deformation. It is then suggested that the prediction of stenting behavior without considering the crimping process might underestimate the stent performance of holding the diseased lesion open.

This study systematically investigated the stent-artery interactions to quantify the impact of stent overexpansion, crimping, as well as elastic recoil on its performance. An increase in degree of stent overexpansion was found to be capable of increasing the final stent diameter, however, it resulted in larger stent recoil as well as higher arterial stresses. The crimping process is necessary for better surgical planning. A few simplifications were made in this work, such as the displacement-controlled balloon expansion technique, idealized artery and plaque geometry, the homogeneous isotropic constitutive model of the lesion, and no blood flow. Although a detailed pressure-driven folded balloon technique could provide better transient behavior of the stent, such as the dogbone shape during the expansion process, it has minimal influence on the balloon-stent-artery interactions at the final state of each phase [23]. A patient-specific geometrical model, fluidstructure interaction, as well as considering the inherent anisotropy and layer-specific properties of the lesion, will alter the magnitude of the dogboning effect, recoil ratio, and arterial stress distributions. However, considering the comparative essence of this work, the impact of modeling techniques of the stenting procedure on the performance of the stent implantations was justified.

\section{Acknowledgment}

The authors are grateful for funding from the National Science Foundation under Grant No. 0926880. None of the authors has any conflict of interest.

\section{References}

[1] Oesterle, S. N., Whitbourn, R., Fitzgerald, P. J., Yeung, A. C., Stertzer, S. H., Dake, M. D., Yock, P. G., and Virmani, R., 1998, "The Stent Decade: 1987 to 1997. Stanford Stent Summit faculty," Am. Heart J., 136(4), Part 1, pp. 578-599.

[2] Rogers, C., and Edelman, E. R., 1995, "Endovascular Stent Design Dictates Experimental Restenosis and Thrombosis," Circulation, 91(12), pp. 2995-3001.

[3] Gu, L. X., Zhao, S. J., Muttyam, A. K., and Hammel, J. M., 2010, "The Relation Between the Arterial Stress and Restenosis Rate After Coronary Stenting," J. Med. Devices, 4(3), pp. 0310051-7.

[4] Timmins, L. H., Miller, M. W., Clubb, F. J., and Moore, J. E., 2011, "Increased Artery Wall Stress Post-Stenting Leads to Greater Intimal Thickening," Lab. Invest., 91(6), pp. 955-967.

[5] Migliavacca, F., Petrini, L., Massarotti, P., Schievano, S., Auricchio, F., and Dubini, G., 2004, "Stainless and Shape Memory Alloy Coronary Stents: A Computational Study on the Interaction With the Vascular Wall," Biomech. Model Mechanobiol., 2(4), pp. 205-217.

[6] Lally, C., Dolan, F., and Prendergast, P. J., 2005, "Cardiovascular Stent Design and Vessel Stresses: A Finite Element Analysis," J. Biomech., 38(8), pp. 1574-1581. 
[7] Wu, W., Wang, W. Q., Yang, D. Z., and Qi, M., 2007, "Stent Expansion in Curved Vessel and Their Interactions: A Finite Element Analysis," J. Biomech., 40(11), pp. 2580-2585.

[8] Gijsen, F. J., Migliavacca, F., Schievano, S., Socci, L., Petrini, L., Thury, A., Wentzel, J. J., van der Steen, A. F. Serruys, P. W., and Dubini, G., 2008, "Simulation of Stent Deployment in a Realistic Human Coronary Artery," Biomed. Eng. Online, 7, pp. 23.

[9] Liang, D. K., Yang, D. Z., Qi, M., and Wang, W. Q., 2005, "Finite Element Analysis of the Implantation of a Balloon-Expandable Stent in a Stenosed Artery," Int. J. Cardiol., 104(3), pp. 314-318.

[10] Dombe, D. D., Anitha, T., Giri, P. A., Dombe, S. D., and Ambiye, M. V., 2012, "Clinically Relevant Morphometric Analysis of Left Coronary Artery," Int. J. Biol. Med. Res., 3(1), pp. 1327-1330.

[11] Fayad, Z. A., Fuster, V., Fallon, J. T., Jayasundera, T., Worthley, S. G., Helft, G., Aguinaldo, J. G., Badimon, J. J., and Sharma, S. K., 2000, "Noninvasive in vivo Human Coronary Artery Lumen and Wall Imaging Using Black-Blood Magnetic Resonance Imaging," Circulation, 102(5), pp. 506-510.

[12] Zhao, S. J., Gu, L. X., Hammel, J. M., and Lang, H., 2010, "Mechanical Behavior of Porcine Pulmonary Artery," in Proceedings of the ASME 2010 International Mechanical Engineering Congress and Exposition; Vancouver, British Columbia, Vol. 2, pp. 771-775.

[13] Pericevic, I., Lally, C., Toner, D., and Kelly, D. J., 2009, “The Influence of Plaque Composition on Underlying Arterial Wall Stress During Stent Expansion: The Case for Lesion-Specific Stents," Med. Eng. Phys., 31(4), pp. 428-433.

[14] Auricchio, F., Diloreto, M., and Sacco, E., 2001, "Finite Element Analysis of a Stenotic Artery Revascularization Through Stent Insertion," Comput. Methods Biomech. Biomed. Eng., 4, pp. 249-263.

[15] Gastaldi, D., Morlacchi, S., Nichetti, R., Capelli, C., Dubini, G., Petrini, L., and Migliavacca, F., 2010, "Modelling of the Provisional Side-Branch Stenting Approach for the Treatment of Atherosclerotic Coronary Bifurcations: Effects of Stent Positioning," Biomech. Model Mechanobiol., 9(5), pp. 551-561.

[16] Avdeev, I., and Shams, M., 2010, "Vascular Stents: Coupling Full 3-D With Reduced-Order Structural Models," IOP Conf. Ser. Mater. Sci. Eng., 10, p. 012133 .

[17] Dunn, A., Zaveri, T., Keselowsky, B, and Sawyer, W, 2007, "Macroscopic Friction Coefficient Measurements on Living Endothelial Cells," Tribol. Lett. 27(2), pp. 233-238.

[18] Carrozza, Jr., J. P., Hosley, S. E., Cohen, D. J., and Baim, D. S., 1999, "in vivo Assessment of Stent Expansion and Recoil in Normal Porcine Coronary Arteries: Differential Outcome by Stent Design," Circulation, 100(7), pp. $756-760$.
[19] Hsiao, H. M., and Chiu, Y. H., 2012, "Assessment of Mechanical Integrity for Drug-Eluting Renal Stent With Micro-Sized Drug Reservoirs," Comput. Methods Biomech. Biomed. Eng.

[20] Lim, D., Cho, S. K., Park, W. P., Kristensson, A., Ko, J. Y., Al-Hassani, S. T., and Kim, H. S., 2008, "Suggestion of Potential Stent Design Parameters to Reduce Restenosis Risk Driven by Foreshortening or Dogboning Due to NonUniform Balloon-Stent Expansion," Ann. Biomed. Eng., 36(7), pp. 1118-1129.

[21] Mortier, P., De Beule, M., Carlier, S. G., Van Impe, R., Verhegghe, B., an Verdonck, P., 2008, "Numerical Study of the Uniformity of BalloonExpandable Stent Deployment," J. Biomech. Eng., 130(2), p. 021018.

[22] Zahedmanesh, H., John Kelly, D., and Lally, C., 2010, "Simulation of a Balloon Expandable Stent in a Realistic Coronary Artery-Determination of the Optimum Modelling Strategy," J. Biomech., 43(11), pp. 2126-2132.

[23] De Beule, M., Mortier, P., Carlier, S. G., Verhegghe, B., Van Impe, R., and Verdonck, P., 2008, "Realistic Finite Element-Based Stent Design: The Impact of Balloon Folding," J. Biomech., 41(2), pp. 383-389.

[24] Mortier, P., De Beule, M., Segers, P., Verdonck, P., and Verhegghe, B., 2011, "Virtual Bench Testing of New Generation Coronary Stents," EuroIntervention, 7(3), pp. 369-376.

[25] Zahedmanesh, H. and Lally, C., 2009 "Determination of the Influence of Stent Strut Thickness Using the Finite Element Method: Implications for Vascular Injury and In-Stent Restenosis,” Med. Biol. Eng. Comput., 47(4), pp. 385-393.

[26] Bermejo, J., Botas, J., Garcia, E., Elizaga, J., Osende, J., Soriano, J., Abeytua, M., and Delcan, J. L., 1998, "Mechanisms of Residual Lumen Stenosis After High-Pressure Stent Implantation: A Quantitative Coronary Angiography and Intravascular Ultrasound Study," Circulation, 98(2), pp. 112-118.

[27] Hanawa, T., 2009, "Materials for Metallic Stents," J. Artif. Organs, 12(2), pp. 73-79.

[28] Scherer, S., Treichel, T., Ritter, N., Triebel, G., Drossel, W. G., and Burgert, O., 2011, "Surgical Stent Planning: Simulation Parameter Study for Models Based on DICOM Standards," Int. J. Comput. Assist. Radiol. Surg., 6(3), pp. 319-327.

[29] Rechavia, E., Litvack, F., Macko, G., and Eigler, N. L., 1995, "Influence of Expanded Balloon Diameter on Palmaz-Schatz Stent Recoil," Cathet. Cardiovasc. Diagn., 36(1), pp. 11-16.

[30] Dumoulin, C., and Cochelin, B., 2000, "Mechanical Behaviour Modelling of Balloon-Expandable Stents,” J. Biomech., 33(11), pp. 1461-1470.

[31] Holzapfel, G. A., Stadler, M., and Gasser, T. C., 2005, "Changes in the Mechanical Environment of Stenotic Arteries During Interaction With Stents: Computationa Assessment of Parametric Stent Designs," J. Biomech. Eng., 127(1), pp. 166-180.

[32] Moller, D., Reimers, W., Pyzalla, A., and Fischer, A., 2001, "Residual Stresses in Coronary Artery Stents," J. Biomed. Mater. Res., 58(1), pp. 69-74. 